\title{
Bilateral abducens nerve palsy in an infant case of fulminant acute disseminated encephalomyelitis: a case report
}

\author{
Zhiliang Yang ${ }^{*}$ and Guilian Sun
}

\begin{abstract}
Background: Sixth (abducens) nerve palsy (ANP) is far less frequent in children and has not been reported as a sign of acute disseminated encephalomyelitis (ADEM). We present an infant case of ADEM with bilateral abducens nerve palsy (BANP).

Case presentation: We report one case of BANP in a 15-month-old boy of fulminant ADEM. The patient underwent physical examinations and brain MRI scan three times during about six months follow-up. The patient had BANP and developmental regression when he regained consciousness from a coma, and the signs had persisted for 6-months.
\end{abstract}

Conclusions: BANP can be a symptom of ADEM.

Keywords: Fulminant acute disseminated encephalomyelitis, Abducens nerve palsy, Case report, Infant

\section{Background}

Acute disseminated encephalomyelitis (ADEM) is an autoimmune inflammatory disorder of the central nervous system. The etiopathogenesis is thought to be immunemediated. It mostly follows an antecedent infection and, rarely, an immunization [1]. The average age of onset is between 6 and 8 years and the disease is much less common in children younger than 2 years [2]. Clinical features are manifold and not pathognomonic.

Sixth (abducens) nerve palsy (ANP) is far less frequent in children. Common causes include trauma, raised intracranial pressure, and neoplasms [3]. Here, we report a rare case of ADEM in a 15-month-old boy who fell into a coma after a seizure. He had bilateral abducens nerve palsy (BANP) and developmental regression when he regained consciousness. To our knowledge, no cases of ADEM with BANP have been reported.

\section{Case presentation}

A 15-month-old normal developmental Chinese boy was brought to our hospital with the chief complaints of

\footnotetext{
* Correspondence: sizhewujiu@163.com

Department of Pediatrics, The First Affiliated Hospital of China Medical University, No. 155 Nanjing North Street, Heping District, Shenyang 110001, Liaoning, China
}

having a fever for 3 days in the morning, and then one given with intravenous antibiotic (ceftriaxone) at the clinic before hospitalization. He was first diagnosed with encephalitis.

A brain MRI scan was also performed urgently. The MRI images showed inhomogeneous areas of increased signal in T2-weighted images in the dorsal part of pons, midbrain, medulla, bilateral thalamus, and right frontal cortex and left cerebellar hemispheres (Fig. 1-1). An electroencephalogram revealed generalized cerebral dysfunction with no definitive irritable foci. Initial investigations revealed a white blood count of $3.4 \times 10^{9} / \mathrm{L}$ $\left(4-10 \times 10^{9} / \mathrm{L}\right)$, hemoglobin of $125 \mathrm{~g} / \mathrm{L}(120-140 \mathrm{~g} / \mathrm{L})$, platelet count of $180 \times 10^{9} / \mathrm{L}\left(10-30 \times 10^{9} / \mathrm{L}\right)$, C-reactive protein of $16.7 \mathrm{mg} / \mathrm{dL}(0-8 \mathrm{mg} / \mathrm{dL})$, ceruloplasmin of $260 \mathrm{mg} / \mathrm{L}(220-330 \mathrm{mg} / \mathrm{L})$, and lactic acid level of $7.0 \mathrm{mg} / \mathrm{L}(3-10 \mathrm{mg} / \mathrm{dL})$. Fundoscopy was normal and the opening pressure on lumbar puncture was $55 \mathrm{mmH}_{2} \mathrm{O}$. Lumbar puncture revealed that the cerebral spinal fluid 
1

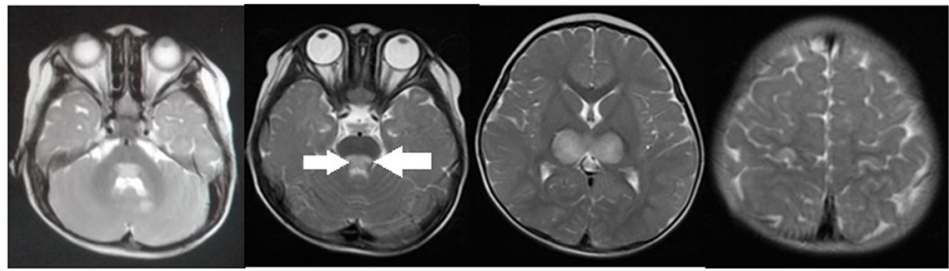

2

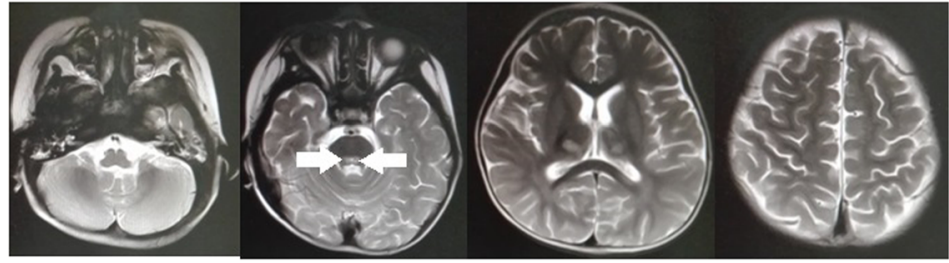

3

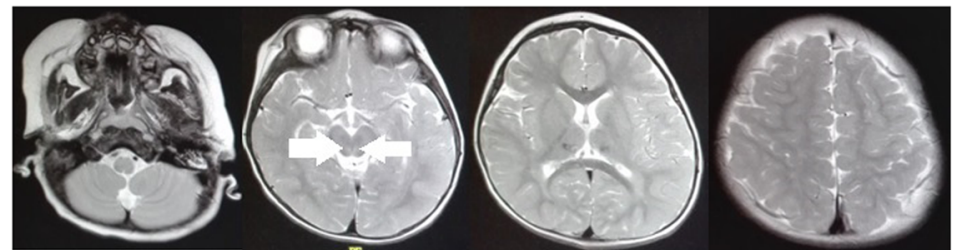

Fig. 1 The brain T2-weighted MRI images. The leisions in the dorsal part of pons (arrows) were considered to cause the bilateral abducens palsy. 1: T2-weighted MRI image showing areas of hyperintensity involving the left cerebellar hemisphere, the dorsal part of pons, thalamus, and right frontal lobe. 2: T2-weighted MRI image after 15 days showing areas of hyperintensity that still involved the dorsal part of pons and thalamus, but not the left cerebellar hemisphere and right frontal lobe. 3: T2-weighted MRI image after 6 months showing areas of hypointensity involving the dorsal part of pons and thalamus

(CSF) cell count was $3 \times 10^{6} / \mathrm{L}$ cells (67 \% lymphocytes, $33 \%$ neutrophils), protein was $604 \mathrm{mg} / \mathrm{L}$, and glucose was $3.4 \mathrm{mmol} / \mathrm{L}$ (capillary blood glucose was $4.1 \mathrm{mmol} / \mathrm{L}$ ), and chloride was $114 \mathrm{mmol} / \mathrm{L}$. Tests of immunoglobin $\mathrm{M}$ for coxsackie virus, herpes virus, cytomegalovirus, toxoplasmosis gondii, rubella virus, adenovirus, respiratory syncytial virus, and Mycoplasma pneumoniae were negative. The diagnosis of ADEM was considered.

He was started on intravenous methylprednisolone ( $250 \mathrm{mg}$, about $25 \mathrm{mg} / \mathrm{kg}$ per day) pulse therapy for 3 days and intravenous immunoglobin (IVIG; $5 \mathrm{~g}$ per day, about $400 \mathrm{mg} / \mathrm{kg}$ per day) for 5 days. Supportive therapies such as nasal feeding and neurotrophic drugs were applied. Hypodermic injection of interferon- $\alpha 1 b$ was also applied. The methylprednisolone pulse therapy was followed with intravenous methylprednisolone $20 \mathrm{mg} /$ day (about $2 \mathrm{mg}$ / $\mathrm{kg}$ per day) because he was unable to take prednisone orally. He showed a good response. On day 3 after starting methylprednisolone pulse therapy and IVIG, he cried and opened his eyes when a subcutaneous injection was given. The GCS was 7/15 (E4V2M1). On day 5, the GCS was 10/ 15 (E4V2M4). His eyeballs could move up and down, but not left and right following a light, without the presence of nystagmus, BANP was suspected. He could follow what his parents said to him and looked in the direction of their voices. however, he was too young to answer some questions. A neurological examination revealed that he could not control his head well.
On day 20, the power in his upper and lower limbs were about IV/V, and he could control his head better, turn over, and crawl a little, but he could not sit or stand unsupported. The MRI imaging of brain and spinal cord were checked. Increased signal in T2-weighted images (Fig. 1-2) was still observed in the bilateral thalamus, the dorsal part of pons, midbrain still, and no abnormal signals were seen in the spinal cord.

The boy was discharged on day 22. At the time of discharge, he was clear consciousness, with a GCS of 11/15 (E4 V2 M5). Oral prednisone $5 \mathrm{mg}$ was given twice daily for about one month, then tapered to $5 \mathrm{mg}$ once daily for about one month and finally to $5 \mathrm{mg}$ every two days.

Three months after the onset, he could sit without support but still could not walk without assistance. He also showed ataxia when he tried to grab something with his hands. Both eyes showed esotropia and could not abduce horizontally, which was compatible with the lesion in the the dorsal part of pons in images, and acquired central BANP was confirmed. At the 6-month follow-up, the MRI images (Fig. 1-3) showed hypointensity involving the the dorsal part of pons and thalamus, and the child's movement disablement and fixed esotropia still existed.

\section{Discussion}

The annual incidence of ADEM is presumed to be 0.8 / 100,000 persons. ADEM may begin abruptly, acutely, or 
over a period of a few days, typically within 1 to 2 weeks following an antigenic challenge. Neurological symptoms typically evolve over several days in ADEM, and alterations in consciousness may range from mild irritability or somnolence to prominent behavioral change or coma [4]. There are no specific biomarkers currently available to diagnose ADEM, hence, diagnosis is made after excluding clinical and laboratory findings, and relies on suggestive neuroradiological features of ADEM.

To exclude hereditary metabolic diseases, blood ceruloplasmin and lactic acid levels were tested and were normal. CSF is usually normal, and a mild elevation of protein with lymphocytic pleocytosis may sometimes be found. Our case had mild elevation of CSF protein without abnormal cells. Some studies have suggested that bilateral thalamic lesions on MRI images may be diagnostic for ADEM [5-7]. In our case, the brain MRI showed lesions in the pons, midbrain, medulla, bilateral thalamus, right frontal cortex, and left cerebellar hemisphere. The lesions in the bilateral thalamus were larger than $2 \mathrm{~cm}$ and tumefactive, which were the most important features for the diagnosis in our case. The diagnosis of our patient was based on his clinical presentation with fever, altered level of consciousness, motor deficits, and brain imaging findings, according to the revised ADEM definitions in 2013 [8].

Signs of cranial nerve involvement are present in 20$37 \%$ of patient with ADEM $[9,10]$, but ANP has not been reported. In our case, the child's eyeballs were able to move up and down, but not left and right following a light after he regained consciousness. After about 2 months, esotropia was observed and his eyeballs could not abduce horizontally. The lesions in the bilateral thalamus and pons still existed at the 6-month follow-up. The leisions in the dorsal part of pons are compatible with the locations of abducens nucleus. The lesions in the abducens nucleus were considered, acquired central BANP could be confirmed.

\section{Conclusions}

We report the case of an infant with fulminant ADEM that showed fixed esotropia and marked developmental regression during 6 months. The BANP and developmental regression can be symptoms of ADEM in infants.

\section{Abbreviations}

ADEM: Acute disseminated encephalomyelitis; ANP: Abducens nerve palsy; BANP: Bilateral abducens nerve palsy; CSF: Cerebral spinal fluid; GCS: Glasgow coma score; IVIG: Intravenous immunoglobin

\section{Acknowledgements}

Not Applicable.

Funding

No funding was obtained for this study.
Availability of data and materials

All data have been presented within the manuscript and in the form of images.

\section{Authors' contributions}

$Z Y$ is responsible for acquisition of the clinical information and writing up of the manuscript. GS is responsible for acquisition of the clinical information and reviewing the manuscript. Both authors read and approved the final manuscript.

\section{Competing interests}

The authors declare that they have no competing interests.

\section{Consent for publication}

Written informed consent was obtained from the patient's parents for publication of this case report and any accompanying images. A copy of the written consent is available for review by the Editor of this journal.

\section{Ethics approval and consent to participate}

Not Applicable.

Received: 8 June 2016 Accepted: 14 October 2016

Published online: 26 October 2016

\section{References}

1. Esposito S, Di Pietro GM, Madini B, Mastrolia MV, Rigante D. A spectrum of inflammation and demyelinization in acute disseminated encephalomyelitis (ADEM) of children. Autoimmun Rev. 2015;14(10):923-9.

2. Mohsen H, Abu Zeinah GF, Elsotouhy AH, Mohamed K. Acute disseminated encephalomyelitis following infectious mononucleosis in a toddler. BMJ Case Rep. 2013; doi: 10.1136/bcr-2013-010048.

3. Merino P, Gómez de Liaño P, Villalobo JM, Franco G, Gómez de Liaño R. Etiology and treatment of pediatric sixth nerve palsy. J AAPOS. 2010;14(6):502-5.

4. Rahmlow MR, Kantarci O. Fulminant demyelinating diseases. Neurohospitalist. 2013:3(2):81-91.

5. Murthy JM. Acute disseminated encephalomyelitis. Neurol India. 2002; 50(3):238-43.

6. Murthy JM, Yangala R, Meena AK, Jaganmohan RJ. Acute disseminated encephalomyelitis: clinical and MRI study from South India. J Neurol Sci. 1999;165(2):133-8.

7. Alexander M, Murthy JMK. Acute disseminated encephalomyelitis: treatment guidelines. Ann Indian Acad Neurol. 2011;14 Suppl 1:S60-4.

8. Krupp LB, Tardieu M, Amato MP, Banwell B, Chitnis T, Dale RC, et al. International pediatric multiple sclerosis study group criteria for pediatric multiple sclerosis and immune-mediated central nervous system demyelinating disorders: revisions to the 2007 definitions. Mult Scler. 2013;19(10):1261-7.

9. Incecik F, Hergüner MÖ, Altunbaşak Ş. Acute disseminated encephalomyelitis: an evaluation of 15 cases in childhood. Turk J Pediatr. 2013;55(3):253-9.

10. Tenembaum S, Chamoles N, Fejerman N. Acute disseminated encephalomyelitis: a long-term follow-up study of 84 pediatric patients. Neurology. 2002;59(8):1224-31.

Submit your next manuscript to BioMed Central and we will help you at every step:

- We accept pre-submission inquiries

- Our selector tool helps you to find the most relevant journal

- We provide round the clock customer support

- Convenient online submission

- Thorough peer review

- Inclusion in PubMed and all major indexing services

- Maximum visibility for your research 